\title{
How to most effectively expand the global surface ozone observing network
}

\author{
E. D. Sofen ${ }^{1}$, D. Bowdalo ${ }^{1}$, and M. J. Evans ${ }^{1,2}$ \\ ${ }^{1}$ Wolfson Atmospheric Chemistry Laboratories, Department of Chemistry, University of York, \\ York, YO10 5DD, UK \\ ${ }^{2}$ National Centre for Atmospheric Science, Department of Chemistry, University of York, \\ York, YO10 5DD, UK \\ Correspondence to: E. D. Sofen (esofen@gmail.com) and M. J. Evans (mat.evans@york.ac.uk)
}

Received: 15 July 2015 - Published in Atmos. Chem. Phys. Discuss.: 5 August 2015

Revised: 27 December 2015 - Accepted: 18 January 2016 - Published: 9 February 2016

\begin{abstract}
Surface ozone observations with modern instrumentation have been made around the world for more than 40 years. Some of these observations have been made as oneoff activities with short-term, specific science objectives and some have been made as part of wider networks which have provided a foundational infrastructure of data collection, calibration, quality control, and dissemination. These observations provide a fundamental underpinning to our understanding of tropospheric chemistry, air quality policy, atmospherebiosphere interactions, etc. Sofen et al. (2016) brought together eight of these networks to provide a single data set of surface ozone observations. We investigate how representative this combined data set is of global surface ozone using the output from a global atmospheric chemistry model. We estimate that on an area basis, $25 \%$ of the globe is observed (34\% land, $21 \%$ ocean). Whereas Europe and North America have almost complete coverage, other continents, Africa, South America, Australia, and Asia (12-17\%) show significant gaps. Antarctica is surprisingly well observed (78\%). Little monitoring occurs over the oceans, with the tropical and southern oceans particularly poorly represented. The surface ozone over key biomes such as tropical forests and savanna is almost completely unmonitored. A chemical cluster analysis suggests that a significant number of observations are made of polluted air masses, but cleaner air masses whether over the land or ocean (especially again in the tropics) are significantly under-observed. The current network is unlikely to see the impact of the El Niño-Southern Oscillation (ENSO) but may be capable of detecting other planetaryscale signals. Model assessment and validation activities are
\end{abstract}

hampered by a lack of observations in regions where the models differ substantially, as is the ability to monitor likely changes in surface ozone over the next century.

Using our methodology we are able to suggest new sites which would help to close the gap in our ability to measure global surface ozone. An additional 20 surface ozone monitoring sites (a $20 \%$ increase in the World Meteorological Organization Global Atmosphere Watch (WMO GAW) ozone sites or a $1 \%$ increase in the total background network) located on 10 islands and in 10 continental regions would almost double the area observed. The cost of this addition to the network is small compared to other expenditure on atmospheric composition research infrastructure and would provide a significant long-term benefit to our understanding of the composition of the atmosphere, information which will also be available for consideration by air quality control managers and policy makers.

\section{Introduction}

Tropospheric ozone is an air pollutant that impairs human respiratory function (McDonnell et al., 1993; Bell et al., 2004; The Royal Society, 2008) and damages both crops and natural vegetation (Bell and Treshow, 2002). It is a greenhouse gas (Myhre et al., 2013) and plays a central role in tropospheric oxidant chemistry (Finlayson-Pitts and Pitts, 1997). Given that it is relatively easy to measure, the accurate model estimation of the concentration of observed tropospheric ozone is often used (rightly or wrongly) as a 
central assessment for our ability to understand tropospheric chemistry. Over the past 40 years, a number of publicly available surface ozone networks have been created. Some have been created in response to air quality legislation (e.g., USA (CASTNET), Canada (CAPMON), Europe (EMEP)). Others are global in their scope (e.g., World Meteorological Organization Global Atmosphere Watch (WMO GAW)) and are primarily for global atmospheric monitoring of the composition of the atmosphere to study global environmental questions. The size, scope, and locations of the measurement sites within these networks have been determined by a combination of scientific questions, cost, political expediency, serendipity, political necessity, and convenience rather than by a systematic attempt to provide globally coverage. It seems likely that the global distribution of surface ozone is inadequately measured, even by the sum of these networks.

Satellites are able to fill in some of these gaps but they are typically less responsive to changes in the surface concentration of ozone (where human and vegetative impacts occur) than to changes higher in the column, and some form of ground-truthing from relatively simple instrumentation provides an essential validation/verification of these remotely sensed observations.

This lack of global coverage of surface ozone observations is problematic. The composition of the atmosphere is changing due to changes in emission, land use, climate, etc. This is part of an ongoing change since the pre-industrial era. Industrialization has led to increasing concentrations of ozone (Volz and Kley, 1988; Marenco et al., 1994; Staehelin et al., 1994; Cooper et al., 2014) but our record of this change is poor, both temporally (systematic measurements typically are available from the 1980s onwards) and spatially (observations are sparse). As emissions have been altered by human activity, these changes, their implications for the chemistry of the atmosphere, and the further impacts of that chemistry have not been fully observed. Atmospheric composition is continuing to change with emissions of ozone precursors in some regions (North America and Europe) dropping, whereas emissions in other regions (Asia, Africa, South America) are forecast to increase (The Royal Society, 2008). In order to better observe and quantify these ongoing and future changes in a global manner that can enhance our scientific understanding and guide environmental policy, the observational network needs to be fit for this purpose.

Here, we investigate how well the present-day (19712013), publicly available surface ozone observations networks cover the globe and how that surface ozone network may be expanded to improve coverage. We base our assessment on the compilation of surface ozone data made by Sofen et al. (2016). This data set includes sites from WMO GAW, US EPA AQS, CASTNET, EU AirBase, EU EMEP, Canadian NAPS, CAPMON, and EANET. Details of the networks and the location of the sites can be found in Sofen et al. (2016). The data set is quality-controlled to remove urban sites (which are not representative of regional conditions) and sites with poor quality data, leaving 2389 sites. We assume that every site in the data set is currently active. We know that there are measurements from many other locations, but the data are not easily accessible (data are held by many individual principal investigators in a range of different file formats), do not provide a long-term observation (measurements are for short periods of time $<5$ years), or may not be sufficiently quality controlled. The Tropospheric Ozone Assessment Report (TOAR; http://www.igacproject.org/TOAR) is attempting to provide a data framework to collect these data sets, provide some post-processing quality control and allow for dissemination. In the future, TOAR may provide a framework for the inclusion of a much wider set of observations than those used here.

Here, we consider the representativeness of the Sofen et al. (2016) data from the perspective of surface coverage, biosphere/atmosphere interactions, chemical regimes, and chemical transport model evaluation. We then assess the best locations for new sites to improve our understanding of surface ozone and we conclude with a list of locations that we argue would best expand our observing capabilities.

\section{Current spatial coverage}

\subsection{Representativeness}

An idealized network of surface observations would provide measurements at a fine enough spatial resolution to enable the reconstruction of the surface ozone field globally, taking into account the varying lifetime of ozone and local meteorology, at a scale that would be useful for global model studies, trend analysis, monitoring, and impact assessment.

Each ozone measurement site represents not just the mixing ratio of ozone at that point in space, but is also representative of a "footprint" both upwind and downwind of that location. The ozone lifetime and transport patterns determine the extent of this footprint. If the local ozone lifetime is short at that location, a measurement will be representative of a small footprint; if the transport is rapid, a measurement will be representative of a larger footprint. A number of methods can be used to evaluate this footprint. One common approach to determining a site's footprint is to use back trajectories, but this fails to take into account either the spatial and temporal variability in the ozone lifetime or that an ozone measurement is also representative of a region downwind of the site. A similar approach uses a fixed time frame catchment area in a Lagrangian tracer model (e.g., Henne et al., 2010) to define footprints for many European air quality sites, but this also fails to account for how the lifetime of ozone varies across the Earth. Instead, we use an Eulerian forward atmospheric chemical transport model (GEOS-Chem v9-01-03; www.geos-chem.org) (Bey et al., 2001; Parrella et al., 2012) to determine footprints based on areas of similar variability in ozone. We use monthly mean surface ozone concentration 


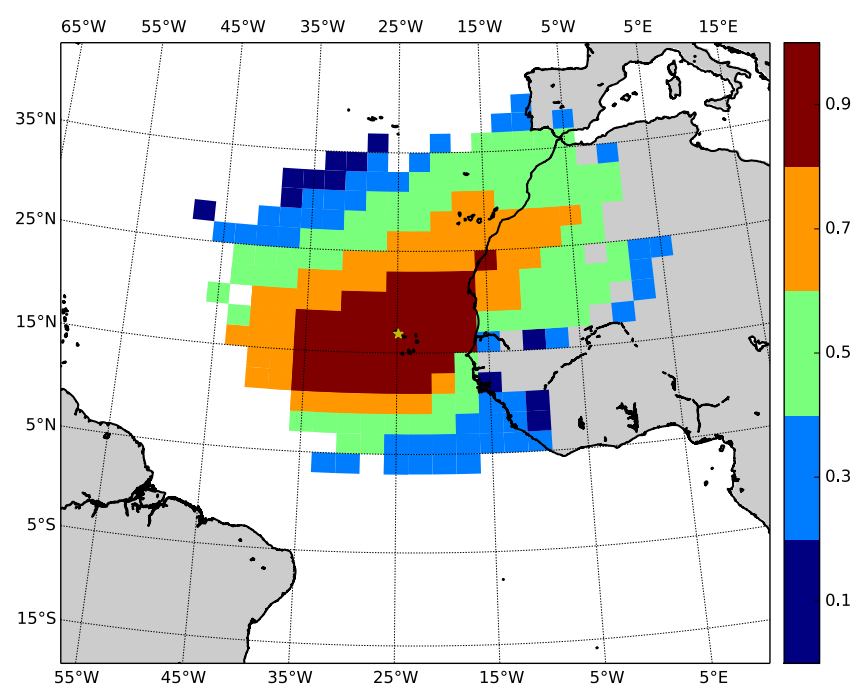

Figure 1. Example of the site footprint for the Cape Verde Observatory (yellow star; $16^{\circ} 51^{\prime} 49^{\prime \prime} \mathrm{N}, 24^{\circ} 52^{\prime} 2^{\prime \prime} \mathrm{W}$ ) derived using thresholds of $R=0.1$ to 0.9 in the spatial correlation of monthly anomalies in surface ozone from the GEOS-Chem model.

calculated using the $2^{\circ} \times 2.5^{\circ}$ version of the model, run from 1 January 2005 to 31 December 2011. We de-seasonalize this output by removing the mean annual cycle from each model grid box. Then for each observing site, we calculate the correlation coefficient $(R)$ between the ozone in that grid box and the ozone in all other model surface grid boxes. The footprint associated with a site is then determined by the model grid boxes with a $R \geq 0.707$. This threshold is chosen such that $R^{2} \geq 0.5$, or at least half the nonseasonal variance in ozone in any grid box in the footprint may be explained by the ozone observation at the observing site. To ensure that the footprint only includes grid boxes contiguous with the observing site, we use a random walk process that goes "downhill" from the observing site until $R<0.707$. The random walk process is allowed to wrap across the International Date Line $\left(180^{\circ}\right)$. We thus assume an area is "observed" from the perspective of ozone if it falls within the footprint of a monitoring site. This footprint approach is similar to that taken by Messié and Chavez (2011) to determine the spatial coherence in sea surface temperature anomalies.

Figure 1 illustrates how the size and shape of the footprint for the Cape Verde Observatory varies as the threshold is changed from 0.1 to 0.9 . There will be some differences in the footprint determination between different model simulations and between different models. However, based on testing with results from the GFDL AM3 model results used for the Atmospheric Chemistry and Climate Model Intercomparison Project (ACCMIP) (Young et al., 2013; Donner et al., 2011) (not shown) we do not believe that this provides a significant uncertainty.

Individual footprints are approximately symmetric upwind and downwind of the observing site. The footprints do not

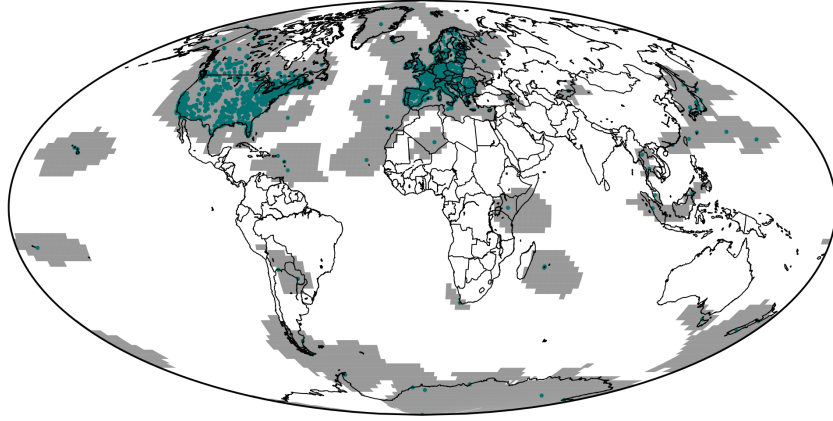

Figure 2. Map of surface ozone observational coverage based on the composite of the footprints for existing background ozone observing sites. Blue markers indicate site locations, and the gray areas their footprints.

represent back trajectories, but instead represent the areas of similar ozone both backward and forward from the observation site. Footprints are typically larger over the ocean where ozone surface deposition is slow and ozone concentrations are more homogenous due to the lack of emissions. They are larger towards the poles than the tropics as ozone lifetimes are longer. Figure 2 shows the coverage map made up of the composite of all of the individual site footprints. Given the present-day network of ozone observations and our evaluation of their global footprint we are now able to evaluate the representativeness of this network. The representativeness however depends on the question that is being addressed. Here we evaluate a range of questions.

1. What fraction of the planet is covered? How is this split between ocean and land? How well observed are the different continents?

2. Which biomes are being monitored?

3. Which atmospheric chemical regimes are being sampled?

4. How useful are these observations for constraining uncertainty in global models?

5. How useful are these sites for observing the predicted future changes in atmospheric composition?

\subsection{Area}

It is obvious from Fig. 2 that the coverage of observations is not global. We find that $25 \%$ of the Earth's surface is covered, $21 \%$ over the oceans and $34 \%$ over the land. Only twice as much of the Northern Hemisphere is covered compared to the Southern Hemisphere (33\% vs. $18 \%$ ), despite $99 \%$ of the observations being in the north. This is due to the larger footprints in the Southern Hemisphere (mainly ocean with low dry deposition rates and long ozone lifetimes) and overlapping footprints in the Northern Hemisphere. While 
the entirety of Europe and $80 \%$ of North America are covered, the other continents are much less well represented with $17 \%$ of South America, $14 \%$ of Oceania and Australia, and $12 \%$ each of Africa and Asia covered. $78 \%$ of Antarctica is represented despite having only seven sites. This is due to the very large footprints associated with these Antarctic sites because (at least in the model) there are no local precursor emissions, no photochemistry during the polar night, uniform deposition, and inadequate springtime ozone destruction, all leading to a very long ozone lifetime and little spatial variability on monthly timescales.

It is evident that the air quality networks in Europe and North America do a good job in representing the regional and background concentrations of ozone. The story for the rest of the world (other than Antarctica) is much more mixed, with $12-17 \%$ of the land area of these continents being monitored. Ocean coverage is generally poor, with the tropical and Southern Hemisphere oceans being particularly poorly observed.

\subsection{Biomes}

The impact of ozone on the biosphere is a critical feedback in the Earth system (Ainsworth et al., 2012). Ozone can diminish plant function and therefore slow carbon dioxide uptake. This may have a significant impact of climate by impacting the terrestrial carbon budget and atmospheric $\mathrm{CO}_{2}$ concentrations (Sitch et al., 2007). Biogenic emissions also play an important role in tropospheric oxidant chemistry, and the chemistry between tropospheric oxidants and biogenic volatile organic compounds is highly complex and uncertain (Lelieveld et al., 2008). Thus, understanding the ozone exposure of different biomes is important when considering the atmosphere-biosphere feedback.

In Fig. 3 we show the global coverage of the current ozone observing capability on a map of terrestrial biomes (Olson and Dinerstein, 2002; The Nature Conservancy, 2012). With North America and Europe completely covered, the temperate grasslands, temperate forests, and North American boreal forests are probably well represented within the ozone observing networks. However, the map reveals that the network lacks coverage over tropical forests, tropi$\mathrm{cal} /$ subtropical grasslands, Eurasian temperate and montane grasslands (e.g., steppe), and the large area of boreal forest across Asia.

Some of these unobserved biomes are critical for the budget of ozone, for the uptake of $\mathrm{CO}_{2}$ (which may be impacted by $\mathrm{O}_{3}$ uptake to plants), and are subject to significant land use change. Given the lack of ongoing monitoring of these biomes, the impact of land use change on composition and vice versa, is not being monitored. The lack of available longterm observations of ozone in the major tropical forested regions of South America, Africa, and Asia appears to be a critical failing of the current network.

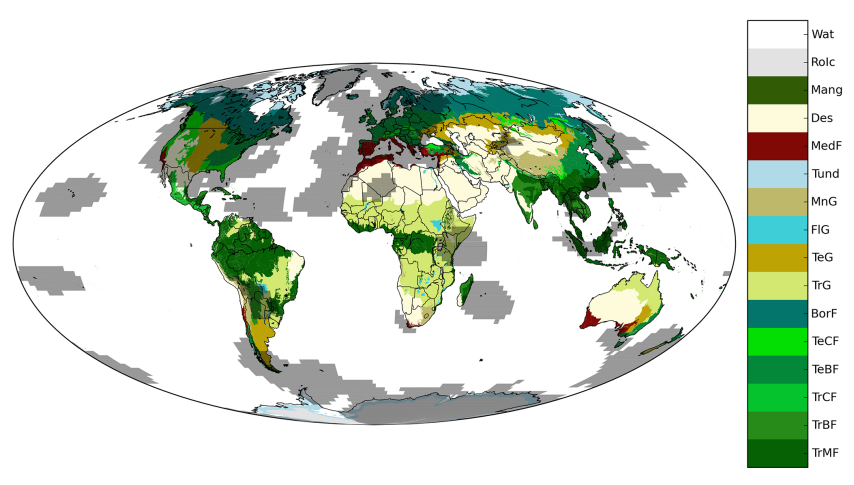

Figure 3. Map of terrestrial biomes (Olson and Dinerstein, 2002; The Nature Conservancy, 2012) shaded by ozone observational coverage. Dark regions of the biomes are areas that are covered by the footprints of ozone sites; light regions do not have ozone observations. Biome abbreviations refer to the following: Wat (water), RoIc (rock and ice), Mang (mangroves), Des (deserts and xeric shrublands), Med (Mediterranean forests, woodlands, and scrubs), Tund (tundra), MnG (montane grasslands and shrublands), FlG (flooded grasslands and savannas), TeG (temperate grasslands, savannas, and shrublands), $\operatorname{TrG}$ (tropical and subtropical grasslands, savannas, and shrublands), BorF (boreal forests/taiga), TeCF (temperate conifer forests), TeBF (temperate broadleaf and mixed forests), TrCF (tropical and subtropical coniferous forests), TrBF (tropical and subtropical dry broadleaf forests), and TrMF (tropical and subtropical moist broadleaf forests).

\subsection{Chemical regimes}

The previous assessments have focused on the geographical distribution of measurements (latitude, longitude). However, the atmosphere could also be split in terms of chemical coordinates. We use a cluster analysis approach applied to chemical transport model output to define chemical regimes and explore how well the different chemical regimes are being observed. From a 1-year GEOS-Chem full chemistry $\left(\mathrm{NO}_{x}-\right.$ $\mathrm{O}_{x}-\mathrm{BrO}_{x}-\mathrm{HC}$-aerosol) simulation ( $\mathrm{v} 9-01-03 ; 2^{\circ} \times 2.5^{\circ}$ ), we extract monthly mean concentrations of all chemical tracers as well as the photolysis rate of ozone and concentration of $\mathrm{OH}$. We exclude sea salt and carbonaceous aerosol species as they occur at very low concentration (model precision) in some grid boxes. Logs of the concentrations are taken of the remaining 52 species $(x)$ and they are then normalized (so that $\overline{\log _{10} x}=0$ and $\sigma_{\log _{10} x}=1$ ). A $k$-mean cluster analysis (Pedregosa et al., 2011) on the normalized logged model concentrations determines areas of similar chemistry. $K$-mean clustering groups data into $k$ clusters based on the Euclidian distance, in this case into normalized chemical concentration space, between each data point and the mean of each cluster. Using 10 to 15 clusters produces qualitatively understandable chemical regimes. The chemical regimes using 12 clusters are illustrated in Fig. 4a. In Fig. 4b, a bar chart shows the total global surface area and the observed area of each cluster. 


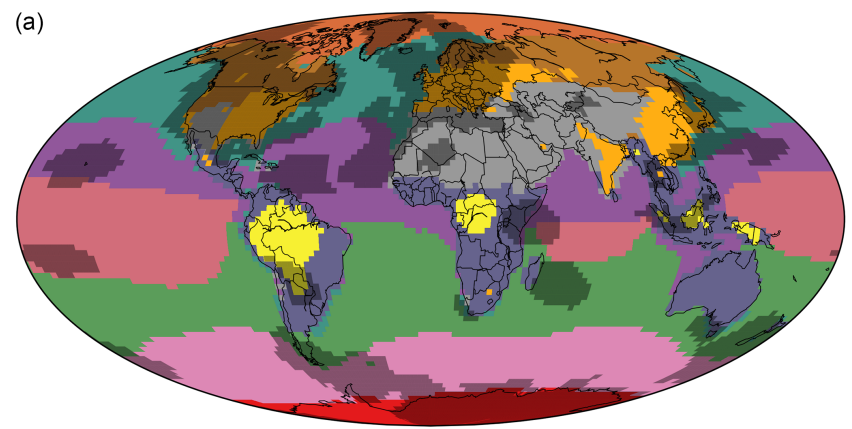

(b)

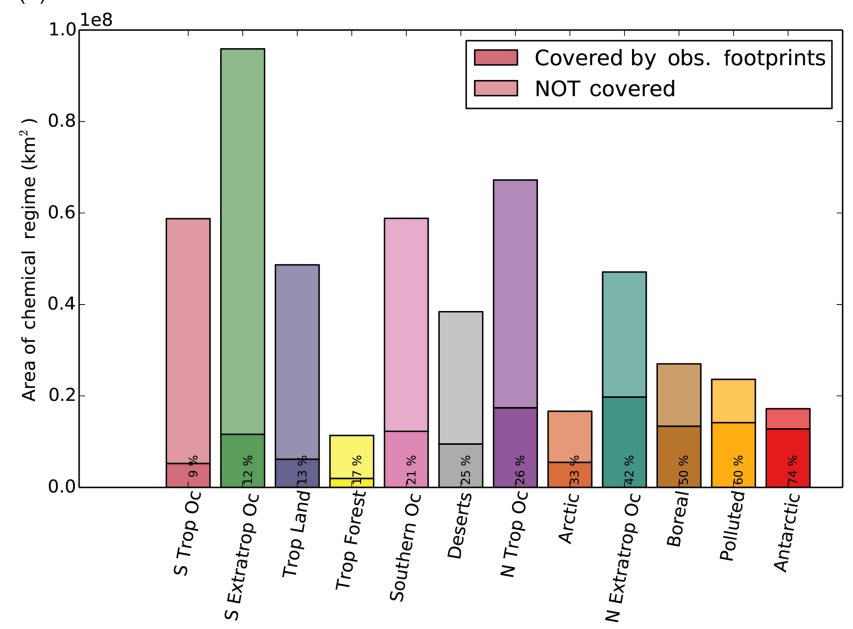

Figure 4. Chemical regimes defined by a cluster analysis of GEOSChem tracers. Panel (a) shows a map of the chemical regimes, with shading indicating areas covered by the footprints of existing ozone sites. In (b), the area of each chemical regime from (a) that is covered (dark) or is not covered (light) by the footprints of ozone observing sites is shown. The bars are ordered by increasing fractional coverage shown above the regime label.

The regimes are spatially coherent, while also reflecting similar chemistry across multiple regions. For example, the northeastern USA, western Europe, India, and eastern China are classified in the same cluster which we described as "polluted". While there are differences in the chemistry of these regions they are (from the perspective of the model, at least) small compared to the difference with other clusters. We identify clusters associated with polluted regions, biogenic emissions, biomass burning, polar regions, deserts, and several oceanic regions. The oceanic classifications exhibit a zonal banding due to the strong latitudinal and seasonally driven interhemispheric dependence in some of the input tracers.

At least $50 \%$ of boreal, polluted, and Antarctic grid boxes are covered. For the polluted case this reflects the total coverage of polluted grid boxes over Europe, North America, and some of East Asia, but very little coverage from anywhere else in the world. Much of the boreal coverage again comes from European and North American air quality net- works. The large fractional coverage of Antarctica is due to the long lifetime of ozone in this region.

Antarctica's coverage contrasts to that of the Arctic $(36 \%)$. Here a similar number of observations fail to characterize the region due to its proximity to Europe and North America emissions, which leads to higher levels of variability and thus smaller footprints. Northern extratropical oceans $(42 \%)$ are reasonably observed due to measurements made from the European, North American, and East Asian networks that extend beyond the continental regions and from islands in the Atlantic.

All of the other classifications show low coverage. Lowest coverage is by the southern tropical ocean cluster, where only $9 \%$ of the air within that cluster could be considered measured which is achieved by the GAW site in Samoa. Chemically critical environments such as the tropical forest, where fluxes of volatile organic compounds (VOCs) are high and our understanding of the chemistry is poor, are again barely observed.

Similar to the analysis by area and biome, we conclude that we probably have good observations of the composition of Antarctic, polluted, and boreal environments. Virtually all other types of air mass are poorly observed.

\subsection{Climate-chemistry modes of variability}

The composition of the atmosphere responds to changes in emissions, solar radiation, deposition, transport etc. The leading global mode of interannual variability in the transport is the El Niño-Southern Oscillation (ENSO) pattern (Zhang et al., 1997). The impact of ENSO on tropical and extratropical tropospheric ozone has been detected from satellite observations (Ziemke et al., 2010, 2015) and is captured by global models (Oman et al., 2011; Zhang et al., 2015), but has not been observed at the surface. However, the ability of models of atmospheric composition to correctly respond to this large-scale forcing may be a critical test of their performance.

Spectral analysis of the surface ozone from a 30-year chemistry-climate simulation using the ACCMIP GFDL AM3 model simulation (Young et al., 2013; Donner et al., 2011) reveals a peak in the power spectrum at the ENSO timescale of 3.8 years. The spatial pattern of surface ozone anomalies associated with that timescale is shown in Fig. 5. The modeled surface ozone ENSO signal is small (at most, $1.1 \mathrm{ppbv}$ peak-to-trough) with opposite phases between the eastern and western Pacific. The small amplitude may be in part due to the quasi-periodic nature of ENSO. This broadens the peak in the power spectrum and means that the variability associated with the particular frequency shown in Fig. 5 may be a low estimate of total ENSO variability. There are no sites located directly in the area of modeled maximal ENSO variability that could assess its magnitude observationally which probably explains why an ENSO signal has not been observed in surface observations. The existing WMO GAW site 


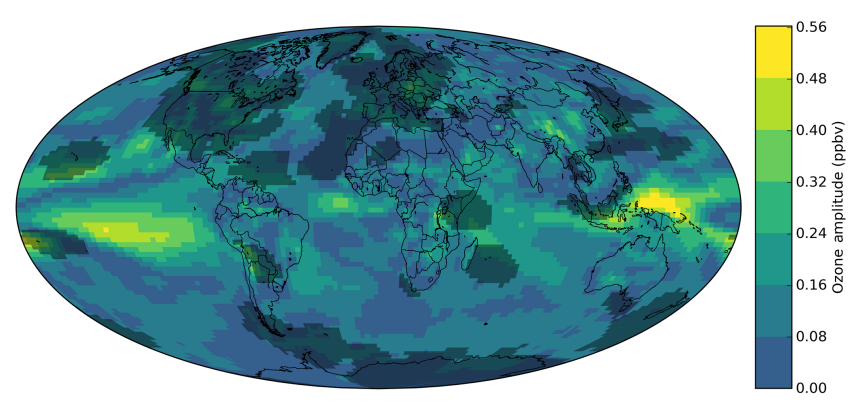

Figure 5. Amplitude of variability (from a spectral/Fourier analysis) in surface ozone at the periodicity of ENSO (1403 days) in a free-running simulation using the GFDL chemistry-climate model.

at Samoa may be able to observe some of the variability but this is outside the region of the largest ENSO signal seen in the model. Making long-term ozone observations from sites such as the Galapagos Islands or the Marquesas Islands in the central Pacific would allow the impact of ENSO on ozone concentrations to be observed. Observations in the western Pacific from islands such as Guam or Palau would also be valuable for this purpose, although the footprints associated with this area are smaller than those in the eastern Pacific.

The second-order patterns of climate variability such as the Arctic Oscillation (Thompson and Wallace, 1998), Atlantic Multidecadal Oscillation, and Pacific Decadal Oscillation (Deser et al., 2010; Messié and Chavez, 2011) are located in the northern Atlantic and Pacific basins with their climate impacts primarily felt in North America and Europe, which are well covered by ozone observations. It should be feasible to investigate the surface ozone response to these signals.

Other large-scale transport flows are the global monsoonal flows. The impact of monsoonal flows on ozone in locations such as India, West Africa, and Southeast Asia (Trenberth et al., 2000; He et al., 2008) are unlikely to be observed in the current observational networks but those in North America will most likely be observed.

\subsection{Model evaluation}

One valuable use for ozone observations is to evaluate the ability of atmospheric chemistry transport models to capture the distribution and variability of ozone. This provides an evaluation of models' ability to aid our assessment of air quality, climate, and fundamental atmospheric chemistry. Tropospheric column evaluations based on satellites or ozone-sondes may be most important for climate purposes, as the column total and vertical distribution determines ozone's potency as a greenhouse gas. However, nearsurface observations are necessary for evaluating the capabilities of chemical transport models with respect to air quality and food security questions. When existing observational data sets are used to evaluate surface ozone, results and the
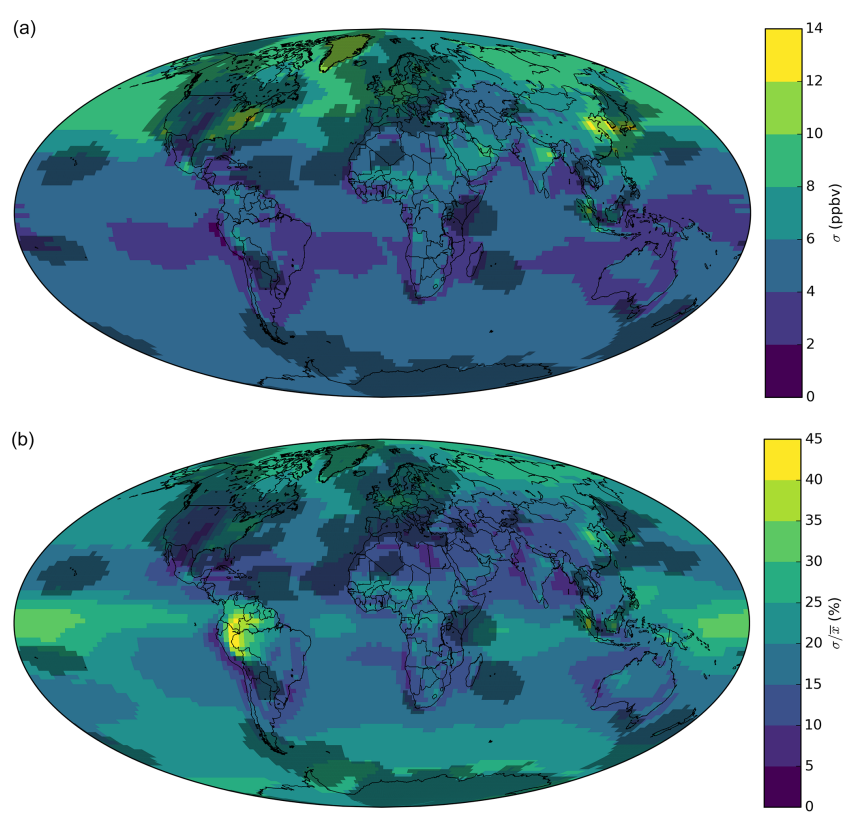

Figure 6. Map of the (a) absolute and (b) fractional standard deviation in annual mean surface ozone between ACCMIP models, following Young et al. (2013). Shaded regions are areas that are covered by the footprints of ozone sites; light regions do not have ozone observations.

conclusions drawn from them may be biased heavily towards the conditions in Europe and North America due to the overwhelming number of observations in these regions. Careful statistical weighting may help to alleviate this bias, but it is made challenging by the varying size of site footprints described above and a corresponding variation in the spatial autocorrelation of observations.

Using the Atmospheric Chemistry and Climate Model Intercomparison Project (ACCMIP) ensemble of model results (Lamarque et al., 2013), we compare the usefulness of the surface ozone network in two ways. Firstly, we investigate the spatial distribution of the inter-model spread in presentday annual mean ozone, which provides an indication of where uncertainty in models is highest, and so where observations may be useful to differentiate between model. Secondly, we look at the projected future trends in ozone, in these same models, to identify regions with large projected changes in ozone concentrations which should be monitored.

\subsubsection{Inter-model variability}

Following the work of Young et al. (2013), we calculate the standard deviation of annual mean surface ozone between eight ACCMIP models (Lamarque et al., 2013) for the present day (2005-2010). Figure 6 shows the ensemble uncertainty (standard deviation between annual means) in both (a) absolute and (b) fractional terms. 
Figure 6a illustrates that the greatest absolute variability between models occurs over industrialized areas of the eastern USA, eastern Asia, and Europe, as well as Greenland and through a general belt across the northern extratropics. Given that the ACCMIP project specified emissions, the differences over polluted industrialized regions probably reflect differences in the model chemistry scheme and the treatment of VOC emissions speciation. These uncertainties appear to be transported through the Northern Hemisphere leading to a wide band of difference between models. The high uncertainty over Greenland is spatially coherent and may reflect issues with the representation of orography between models. Our ability to measure ozone (and so provide a constraint on models) is very good over North America and Europe. There is some capability in East Asia but China is missing. Differences in the northern extratropical Pacific will be unmeasured with the potential for some measurement over the northern extratropical Atlantic. Measurements made over Greenland allow the large variability here to be analyzed.

Different locations become important on a fractional basis. As well as the polluted regions described earlier, large fractional uncertainty occurs over the Amazon and tropical oceans, notably the tropical western Pacific, which are essentially unobserved. Again similar to the comments in the previous sections the addition of a relatively small number of observations in key regions would help to constrain global model uncertainty.

\subsubsection{Trends}

Ozone concentrations are thought to have increased significantly over the twentieth century (Marenco et al., 1994; Staehelin et al., 1994; Cooper et al., 2014), but the magnitude and spatial distribution of this change is uncertain due to a lack of observations over this period. Simulations of future ozone suggest similar changes over the next 50-100 years. However, this time we have the opportunity to monitor this change if observations are made in the correct places.

Figure 7 illustrates the mean changes in surface ozone between 2005-2010 and 2095-2100 in the RCP2.6 and RCP8.5 scenarios in the ACCMIP models (Lamarque et al., 2013). Trends are nearly identical to those calculated by Young et al. (2013). These RCP2.6 and RCP8.5 scenarios suggest opposite trends in surface ozone at 2100 , due to the differing assumptions inherent in the emissions scenarios. Surface ozone in RCP2.6 decreases by 10 ppbv over large swaths of the Northern Hemisphere midlatitudes and up to 15-20 ppbv over the USA. The only areas of increasing ozone in RCP2.6 are over West and Central Africa. While the general drop in surface ozone would be observable with the current network, the increase in West Africa would go unmeasured by the current observational network.

In contrast, the RCP8.5 scenario suggests the potential for 5-7 ppbv increases over polar regions and northern hemispheric oceans and increases of $7-15$ ppbv over portions of
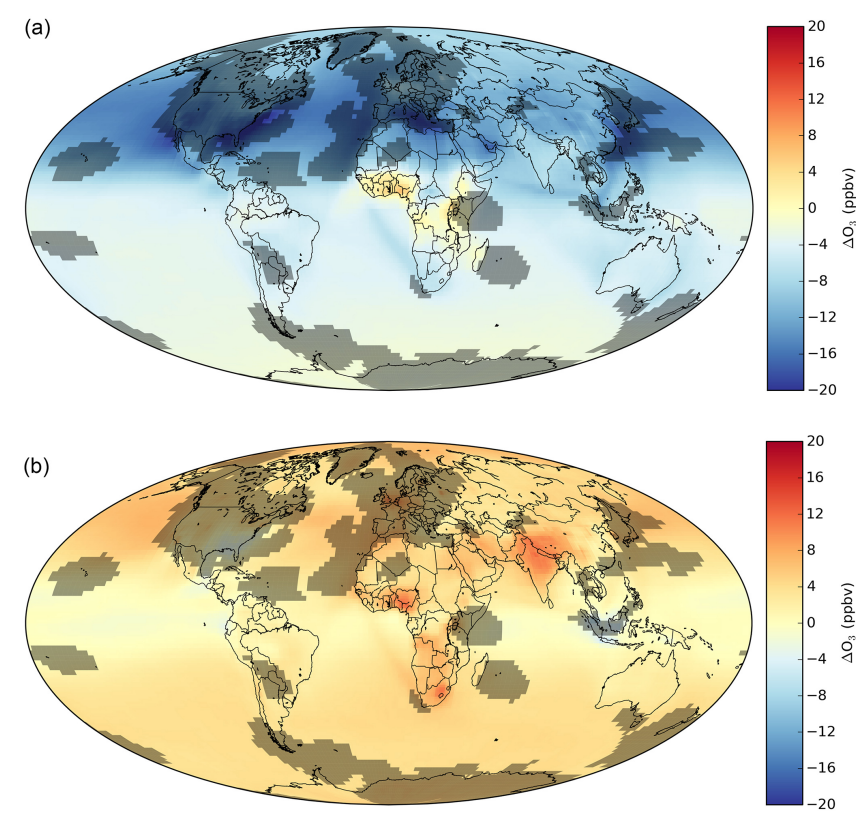

Figure 7. Maps showing the mean trend across ACCMIP models in annual mean surface ozone from 2005-2010 to 2095-2110 for scenarios (a) RCP2.6 and (b) RCP8.5, following Young et al. (2013). Shaded regions are areas that are covered by the footprints of ozone sites; light regions do not have ozone observations.

India, the Middle East, and sub-Saharan Africa, together with an increase in the hemispheric background. Again the current observational network would not be capable of measuring the changes in these locations.

Significant changes are forecast in surface ozone over the next decades. In some regions this change should be observed by the current network (North America and Europe). However, much of this change will occur in regions with no observational capability.

\section{Where to add observations}

From the previous analysis, the current surface ozone monitoring network fails to make measurements in key regions (China, India, Amazon, Africa, tropical oceans, Southern Ocean). This has implications for our ability to understand the processes going on in the atmosphere and provide robust policy advice. There are ongoing efforts to improve the global atmospheric observational capability through the establishment or enhancement of surface sites. There may be a range of reasons for establishing a new ozone monitoring site based on the local political requirements, practicality, finance, and scientific goals, but if they are to be established, basing the site choice on maximizing the global benefit would be a sensible criterion. To aid in this, we evaluate each model grid box which does not currently have an ob- 


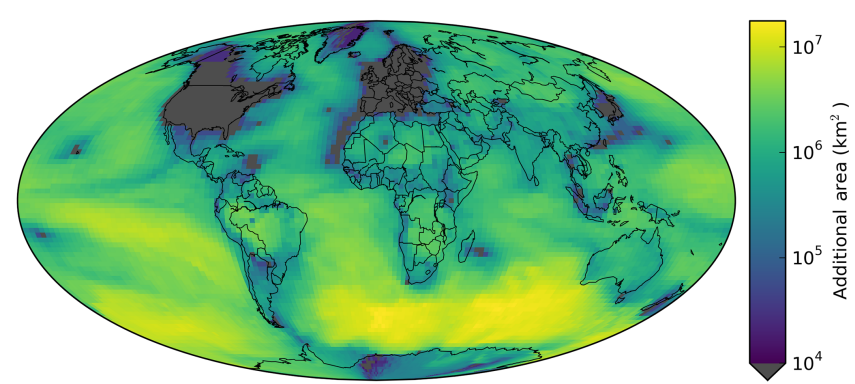

Figure 8. Additional area that a site in each grid box would contribute to the global ozone data coverage calculated based on footprints from GEOS-Chem.

servational site for its potential ability to improve the global measurement network.

Our primary metric for evaluation is the additional surface area that a surface ozone measurement in that location would bring. The additional area is the area of that site's footprint, minus any area already covered by the footprints of existing observing sites. Figure 8 illustrates the amount of additional area that each grid box would add to the global coverage if an ozone monitor were installed there. Areas in gray show no additional benefit from siting an observation there. The lighter the color, the greater the area covered. There is significant variation between sites due to the lifetime of ozone (longer over the ocean than over the land, longer towards the poles than towards the tropics), transport pathways, and the positioning of existing ozone sites.

The areas that would provide the greatest additional contribution to the area coverage of ozone observations come from the Atlantic and Indian sectors of the Southern Ocean. This is due to the large footprint size in those regions, combined with few existing Southern Hemisphere measurements outside of Antarctica. The terrestrial areas that will provide the greatest additional area coverage are northeastern Russia and the southern Amazon basin. Many of these recommended areas also align well with other characteristics related to ozone where we wish to expand coverage (e.g., tropical forest biomes or areas of high inter-model uncertainty).

Figures 9 and 10 show the footprints from the top 10 distinct locations for oceanic and terrestrial areas, respectively. Table 1 summarizes how each of the sites relates to the characteristics described in Sects. 2.2-2.6.2 above.

\subsection{Oceanic sites}

The oceanic sites that could add the most additional area are located over the Southern Ocean, and the tropical and southern subtropical Pacific and Atlantic Oceans (Fig. 9). The challenge in expanding the observing capacity over oceanic regions is finding nearby islands that provide suitable environments and infrastructure for long-term continuous measurements. For ozone measurements, these requirements in-
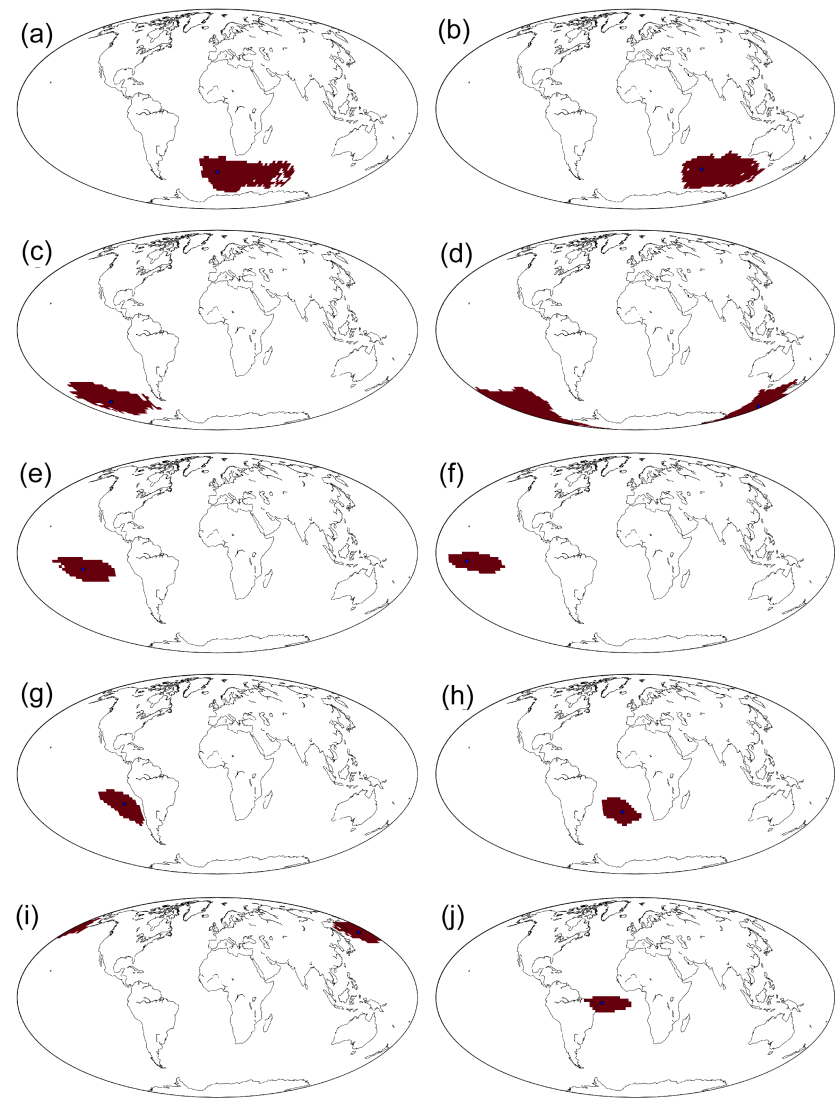

Figure 9. Footprints for the top 10 grid boxes from distinct oceanic areas that will provide the greatest increase in the global coverage of ozone.

clude a steady electricity supply, a temperature-controlled room for the instrument, an internet connection for remote data access, and regular (approximately monthly) or asneeded visits by trained staff.

There are a range of options in the Southern Ocean. In the Atlantic sector, Bouvet Island and South Georgia and the South Sandwich Islands provide potential site locations and presently, all house research stations (British and Norwegian). Peter I Island and Scott Island are the only two options in the Pacific sector. Unfortunately, both are rugged and uninhabited and the only scientific infrastructure is automatic weather stations, making them less suitable options. Near Australia and New Zealand, the Macquarie Island Station is a potential site that would cover portions of the Pacific and Indian sectors of the Southern Ocean. In the Indian Ocean sector, the Crozet Islands have a permanent research station run by the French, the Prince Edward Islands host a South African research station, and the French Kerguelen Islands are populated and host multiple research stations.

In the eastern Pacific, potential islands to host ozone sites include the Pitcairn Islands, Marquesas Islands, and Galapagos Islands. One notable contribution from these locations is that they could potentially capture an ENSO signal in sur- 
Table 1. Summary of potential ozone sites.

\begin{tabular}{|c|c|c|c|c|c|c|c|c|c|c|}
\hline \multirow[t]{2}{*}{ Fig. } & \multirow[t]{2}{*}{ Lat. } & \multirow[t]{2}{*}{ Long. } & \multirow{2}{*}{$\begin{array}{l}\text { Area } \\
\left(10^{6} \mathrm{~km}^{2}\right)\end{array}$} & \multirow{2}{*}{$\begin{array}{l}\text { Nearby islands } \\
\text { or biomes }{ }^{\mathrm{a}}\end{array}$} & \multirow[t]{2}{*}{ Country } & \multirow[t]{2}{*}{ Chem. regimes ${ }^{\mathrm{b}}$} & \multirow[t]{2}{*}{ ENSO } & \multirow{2}{*}{$\begin{array}{l}\text { Inter-model } \\
\text { uncertainty }^{c}\end{array}$} & \multicolumn{2}{|c|}{ Trends } \\
\hline & & & & & & & & & $\mathrm{RCP} 2.6^{\mathrm{d}}$ & $\mathrm{RCP} 8.5^{\mathrm{e}}$ \\
\hline $9 a$ & -47 & 1.25 & 17.3 & Bouvet Is., S. Georgia \& S. Sandwich Is. & Norway, UK & S. Ocean & & $4.8(22.2 \%)$ & -2.7 & 4.3 \\
\hline $9 b$ & -45 & 76.25 & 16.8 & Kerguelen Is. & France & S. Ocean & & $4.7(20.7 \%)$ & -2.6 & 4.4 \\
\hline $9 \mathrm{c}$ & -55 & -136.25 & 11.6 & Peter I Is., Scott Is. & Norway, N.Z. & S. Ocean & & $4.7(21.8 \%)$ & -2.7 & 3.6 \\
\hline $9 \mathrm{~d}$ & -59 & 173.75 & 11.0 & Macquarie Is. & Australia & $\begin{array}{l}\text { S. Ocean, } \\
\text { S. subtrop. oc. }\end{array}$ & & $4.6(21.8 \%)$ & -2.6 & 3.9 \\
\hline $9 \mathrm{e}$ & -11 & -121.25 & 8.3 & Pitcairn Is. & UK & Trop. oc. & Yes & $3.8(20.1 \%)$ & -3.2 & 0.5 \\
\hline $9 \mathrm{f}$ & -5 & -151.25 & 6.6 & Marquesas Is. & France & Trop. oc. & Yes & $4.2(28.8 \%)$ & -3.7 & -0.6 \\
\hline $9 \mathrm{~g}$ & -21 & -86.25 & 6.5 & Galapagos Is. & Ecuador & S. subtrop. oc & Yes & $4.1(17.1 \%)$ & -3.4 & 3.5 \\
\hline $9 \mathrm{~h}$ & -27 & -11.25 & 5.8 & St. Helena, Tristan da Cunha & UK & S. subtrop. oc & & $4.1(16.9 \%)$ & -3.8 & 3.9 \\
\hline $9 \mathrm{i}$ & 51 & 168.75 & 4.8 & Aleutian Is. & USA, Russia & $\begin{array}{l}\text { N. extratrop.oc, } \\
\text { Arctic }\end{array}$ & & $8.4(21.8 \%)$ & -13.1 & 6.1 \\
\hline $9 \mathrm{j}$ & -3 & -28.75 & 4.6 & Ascension Is., Fernando de Noronha & UK, Brazil & S. subtrop. oc & & $5.3(22.1 \%)$ & -4.0 & 0.6 \\
\hline $10 \mathrm{a}$ & -9 & -58.75 & 4.4 & TrMF & Brazil & Trop. forest & & $4.7(24.5 \%)$ & -4.6 & 0.7 \\
\hline $10 \mathrm{~b}$ & 57 & 161.25 & 3.0 & Tund & Russia & Boreal, Arctic & & $7.7(22.4 \%)$ & -10.3 & 4.2 \\
\hline $10 \mathrm{c}$ & -17 & 28.75 & 2.9 & $\operatorname{TrG}$ & Zimbabwe & Trop. land & & $4.5(14.9 \%)$ & -2.7 & 7.0 \\
\hline $10 \mathrm{~d}$ & 43 & 108.75 & 2.4 & Des, TeG, BorF, MnG & Mongolia & Boreal & & $6.6(15.5 \%)$ & -12.5 & 4.3 \\
\hline $10 \mathrm{e}$ & -7 & -38.75 & 2.4 & Des, $\operatorname{TrG}$ & Brazil & Trop. land & & $3.8(16.1 \%)$ & -4.9 & 1.4 \\
\hline $10 \mathrm{f}$ & 61 & 88.75 & 2.4 & BorF, Tund & Russia & Boreal, polluted & & $7.7(23.9 \%)$ & -9.2 & 3.5 \\
\hline $10 \mathrm{~g}$ & 19 & 13.75 & 2.4 & Des, $\operatorname{TrG}$ & Niger & Desert & & $4.3(12.0 \%)$ & -9.6 & 3.8 \\
\hline $10 \mathrm{~h}$ & -3 & 26.25 & 2.3 & TrMF, TrG & DR Congo & Trop. forest & & $4.0(15.2 \%)$ & 0.9 & 4.9 \\
\hline $10 \mathrm{i}$ & 49 & 61.25 & 1.9 & Des, TeG, BorF & Kazakhstan & Desert, polluted & & $5.5(15.3 \%)$ & -11.2 & 3.1 \\
\hline $10 \mathrm{j}$ & -21 & 131.25 & 1.9 & Des, TrG & Australia & Trop. land & & $4.8(19.1 \%)$ & -4.8 & 2.2 \\
\hline
\end{tabular}

a Biomes are not specified for oceanic sites, as islands stations will primarily see marine air. The biomes listed include all the biomes covered in each footprint. Biome abbreviations refer to: Wat (water), RoIc (rock and ice), Mang (mangroves), Des (deserts and xeric shrublands), Med (Mediterranean forests, woodlands and scrubs), Tund (tundra), MnG (montane grasslands and shrublands), FlG (flooded grasslands and savannas), TeG (temperate grasslands, savannas, and shrublands), $\mathrm{TrG}$ (tropical and subtropical grasslands, savannas, and shrublands), BorF (boreal forests/taiga), TeCF (temperate conifer forests), TeBF (temperate broadleaf and mixed forests), $\operatorname{TrCF}$ (tropical and subtropical coniferous forests), $\operatorname{TrBF}$ (tropical and subtropical dry broadleaf forests), and $\operatorname{TrMF}$ (tropical and subtropical moist broadleaf forests). ${ }^{\mathrm{b}}$ The chemical regimes listed include all the chemical regimes covered in each footprint. ${ }^{\mathrm{c}}$ The global area-weighted mean inter-model uncertainty is $5.4 \pm 1.7 \mathrm{ppb}(20 \% \pm 15 \%)$. Bold values indicate sites where the inter-model variability is more than 1 SD (standard deviation) above the global mean. ${ }^{\mathrm{d}}$ The global area-weighted mean trend for RCP2.6 is $-7.0 \pm 4.5 \mathrm{ppb}$. Bold values indicate sites where the local trend is more than 1 SD away from the global mean. ${ }^{\mathrm{e}}$ The global area-weighted mean trend for RCP8.5 is $3.2 \pm 2.1 \mathrm{ppb}$. Bold values indicate sites where the local trend is more than $1 \mathrm{SD}$ away from the global mean.

face ozone. The tropical Pacific also represents the tropical oceanic chemical regime (Fig. 4) that has the least coverage of any of the chemical regimes. The tropical Pacific is also an area of high fractional inter-model spread (Fig. 6b). We are aware of measurements currently being made on the Galapagos Islands (Wang et al., 2014, A. Saiz-Lopez, personal communication, 2015), and the long-term reporting of this data to the GAW network or TOAR data set would provide a significant global benefit.

In the southern and tropical Atlantic Ocean, there are four islands that are good candidates for new ozone sites. St. Helena and Ascension Islands both already host WMO GAW sites. Flask and sonde measurements are already made on a regular basis at the GAW site on Ascension, so there is already technical staff available on the island for the infrequent maintenance of an ozone instrument. The island of Tristan da Cunha is the most remote human settlement on Earth. While it does not host a GAW station, Tristan da Cunha hosts a Comprehensive Test Ban Treaty scientific station that is accompanied by some other instruments such as a Danish Meteorological Institute/Danish National Space Institute magnetometer. Closer to South America is the Brazilian island of Fernando de Noronha, which is a UNESCO World Heritage environmental preservation site $354 \mathrm{~km}$ off the coast of Brazil, but it is populated and has an airport.

The one oceanic area in the Northern Hemisphere that is notably lacking in observations and could provide a large incremental increase in the coverage of the Earth's surface based on Fig. 8 is the North Pacific near the Aleutian Islands. A site in the Aleutian Islands would have a footprint covering the Bering Sea and Kamchatka Peninsula. It could also potentially provide constraints on the large inter-model spread in Northern Hemisphere background marine environments and observe long-range transport of pollution events from Asia.

It appears that a relatively small number (10) of ozone instruments distributed on inhabited islands, many with preexisting scientific research infrastructure, would provide a significant enhancement of the area of the world covered by ozone observations.

\subsection{Continental sites}

The 10 terrestrial sites that provide the greatest additional area coverage are located in the Amazon basin, Central Africa, northern Asia, and Australia (Fig. 10).

The Amazon and Central African sites (Fig. 10a, c, e, h) are tropical forest regions with high biodiversity. These regions are also characterized by very high biogenic and biomass burning emissions and intensive photochemistry (Guenther et al., 2012; Giglio et al., 2013). They are also areas of high inter-model spread (Fig. 6) and high uncertainty in their future trends (Fig. 7) due to uncertainties in both emissions of ozone precursors and chemistry. All of these characteristics point to these regions as important locations for additional atmospheric monitoring. The footprint 
(a)

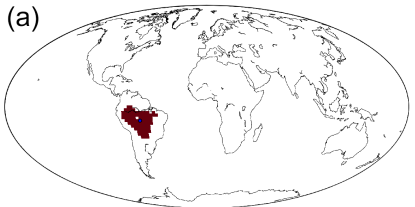

(c)

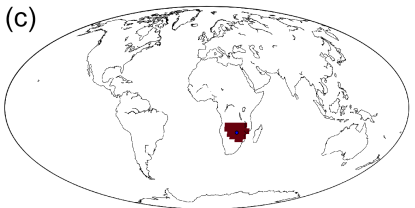

(e)
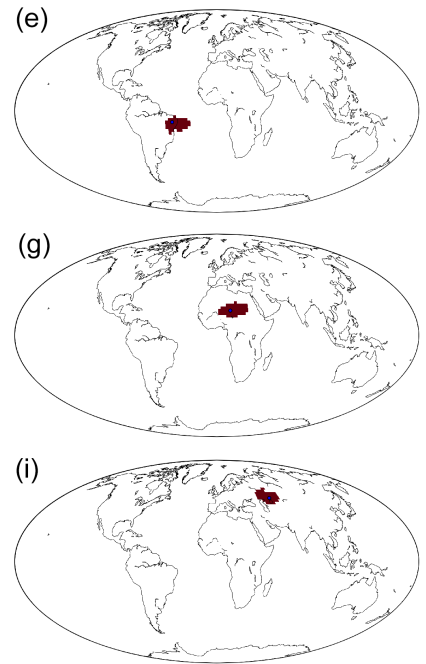

(b)

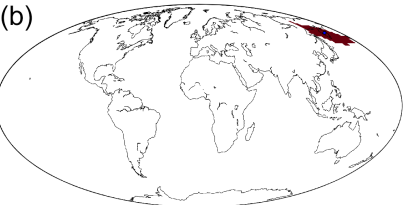

(d)

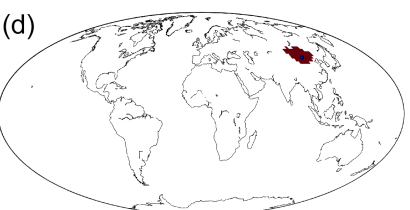

(f)

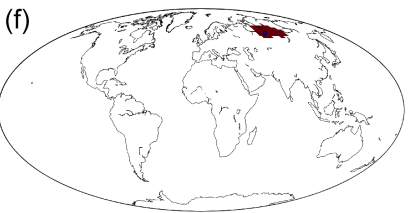

(h)

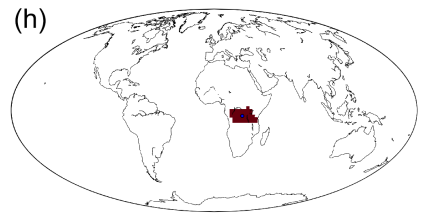

(j)

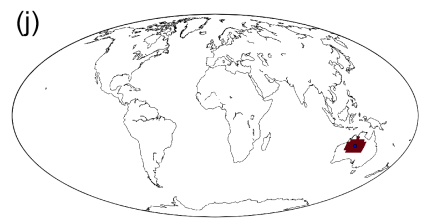

Figure 10. Footprints for the top 10 grid boxes from distinct terrestrial areas that will provide the greatest increase in the global coverage of ozone.

of Fig. 10e is near the WMO GAW global site of Arembe, as well as the long-term ozonesonde site at Natal, Brazil. Near Fig. 10a is the Manaus, Brazil, GAW contributing site.

The North African location (Fig. 10g) is very remote. The nearest WMO GAW global station at Assekrem, Algeria, has been measuring ozone since the year 1997 but measures in a different meteorological regime. Setting up a measurement site in this region would be challenging.

Regions of northern Asia, including Mongolia (Fig. 10d), and the Krasnoyarsk (Fig. 10f) and Kamchatka (Fig. 10b) territories of Russia, would also represent large additions to the area covered by the ozone observing network. The regions are covered by steppe and boreal forest biomes. These regions are, broadly speaking, rugged and remote, but there are existing WMO GAW regional stations in the region. On the Kamchatka Peninsula (Fig. 10b), the PetropavlovskKamchatsky World Ozone and Ultraviolet Radiation Data Centre (WOUDC) station measures total column ozone and solar radiation, as does the Tomsk site in Krasnoyarsk (Fig. 10f). In Mongolia near the location marked in Fig. 10d, there is a regional WMO GAW station at Ulaan Uul that presently collects greenhouse gas flask samples. Figure 10i

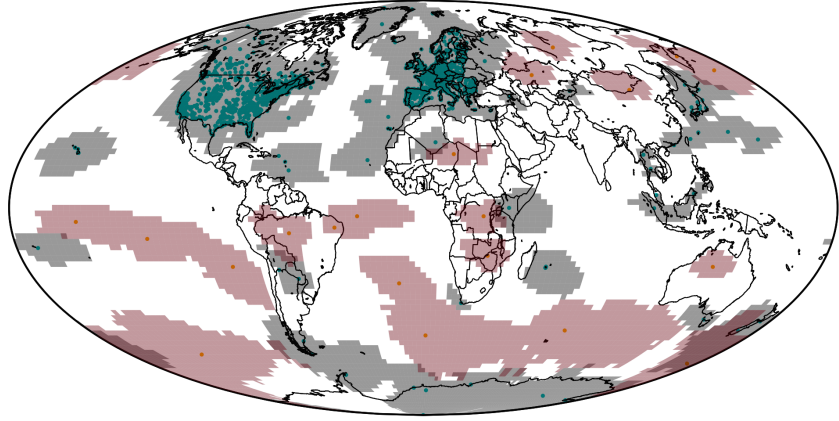

Figure 11. Map of surface ozone observational coverage as in Fig. 2 (blue dots indicate current measurement sites and gray areas their footprints) with the 20 additional sites and footprints from Figs. 9 and 10 added as red dots and pink areas to illustrate the global coverage if ozone measurements were made at these sites.

is further west in Kazakhstan, near the Black Sea. There are several WOUDC stations, but none have reported ozone column data to the WMO in several years.

Finally, we find one location (Fig. 10j) in western Australia. Australia already has a network of ozone sites for air quality monitoring, but data are collected at the state level and are not readily accessible. That said, air quality networks focus on urban air pollution issues, and additional background sites in Australia beyond the WMO GAW site at Cape Grim, Tasmania, are warranted and would bring global benefits. The nearest existing WMO GAW site is located at Darwin, but this is a coastal site that will capture more of the maritime conditions of the Timor Sea.

Unlike the marine sites, establishing ozone measurements at the terrestrial sites may be more problematic. Political and security difficulties will make countries like Zimbabwe, Niger, or the Democratic Republic of the Congo challenging locations to establish long-term ozone monitoring sites. Remote locations in the Sahara or the Eurasian steppe would be logistically challenging. However, the addition of ozone measurements to sites with pre-existing infrastructure, or the inclusion of measurements already being made into international databases would provide significant benefits for relatively little cost.

\subsection{Impact on global coverage}

The global impact of making surface ozone measurements at these additional 20 surface zone monitoring sites is show in red in Fig. 11. The global area coverage would improve from 25 to $44 \%$, with $48 \%$ of the land and $43 \%$ of the ocean covered. Southern Hemisphere coverage is improved, increasing to $49 \%$, surpassing that of the Northern Hemisphere (39\%). Coverage of South America would increase to $40 \%$, African coverage to $30 \%$, Asian coverage to $26 \%$, and Oceania to $30 \%$. Changes over North America and Antarctica are at the $<1 \%$ level. 
A limitation of our approach is that China and India would remain notably unobserved. The high concentrations of pollution (notably $\mathrm{NO}_{x}$ ) in these regions gives ozone a short lifetime and so any additional site in these regions adds little to the global coverage. However, given the variability in the modeled ozone for these regions and their probable trend over the next decades, additional measurement and or reporting of existing measurements is critical. The challenge here is probably to get existing data into publicly accessible databases where they can be further used. For example, China has an extensive air quality monitoring network where current data are publicly available online as Air Quality Index (AQI) values (http://aqicn.org/), but there is no available archive of historical data or direct reporting of concentrations. Until these observations are generally available for scientific evaluation, it is difficult to know where further observations capabilities are needed.

\section{Conclusions}

We have investigated a data set of readily available, longterm surface network ozone data (Sofen et al., 2016) for its global coverage. This coverage can be interpreted in different ways depending upon the science/policy goal and we investigate the coverage from a range of perspectives.

Large countries such as China, India, and Brazil are essentially unrepresented in the Sofen et al. (2016) data set. However, there are increasing efforts to make appropriate measurements in these regions. If these measurements were reported through to a national or international network and the data were made available, they would fill a significant hole in the representation of global surface ozone. The Tropospheric Ozone Assessment Report project (http://www.igacproject. org/TOAR) is attempting to improve access to existing measurements in these regions.

Our analysis shows that the most scientific benefit is probably accrued by making measurements in the forested tropical regions of South America, Africa, and Southeast Asia/Oceania. From a spatial perspective, and probably from a logistical perspective, large benefits would accrue from measurements on islands in the tropics and the Southern Ocean with pre-existing scientific infrastructure. Adding the top 10 maritime and terrestrial sites that contribute the largest additional area to the global coverage increases the fraction of the Earth covered by observing site footprints from 25 to $44 \%$.

We have provided a rather straightforward analysis of the data that begins to provide a structure for the systematic expansion of the network of global surface ozone observations. However, more complex methodologies exist. Just as the scientific utility of new satellites observations is simulated before their launch (Zoogman et al., 2011), more complex methodologies could be applied to find the optimal location for new surface ozone observations. However, it seems unlikely that there is much benefit to be gained from making these observations over North America, Europe, or Antarctica, and there are probably significant benefits in making these relatively cheap and easy observations virtually anywhere else in the world.

Acknowledgements. We acknowledge funding from UK NERC grants NE/K016008/1, NE/L01291X/1. We thank Barron Henderson (University of Florida) for making his bpch and pseudonetcdf code available for processing GEOS-Chem model output in Python.

Edited by: E. Harris

\section{References}

Ainsworth, E. A., Yendrek, C. R., Sitch, S., Collins, W. J., and Emberson, L. D.: The Effects of Tropospheric Ozone on Net Primary Productivity and Implications for Climate Change, Annu. Rev. Plant Biol., 63, 637-661, 2012.

Bell, J. N. B. and Treshow, M. (Eds.): Air pollution and plant life, John Wiley \& Sons Ltd., Chichester, UK, 2nd Edn., 2002.

Bell, M. L., McDermott, A., Zeger, S. L., Samet, J. M., and Dominici, F.: Ozone and short-term mortality in 95 US urban communities, 1987-2000, J. Am. Med. Assoc., 292, 2372-2378, 2004.

Bey, I., Jacob, D. J., Yantosca, R. M., Logan, J. A., Field, B. D., Fiore, A. M., Li, Q., Liu, H. Y., Mickley, L. J., and Schultz, M. G.: Global modeling of tropospheric chemistry with assimilated meteorology: Model description and evaluation, J. Geophys. Res., 106, 23073, doi:10.1029/2001JD000807, 2001.

Cooper, O., Parrish, D. D., Ziemke, J., Balashov, N. V., Cupeiro, M., Galbally, I. E., Gilge, S., Horowitz, L., Jensen, N. R., Lamarque, J.-F., Naik, V., Oltmans, S. J., Schwab, J., Shindell, D. T., Thompson, A. M., Thouret, V., Wang, Y., and Zbinden, R. M.: Global distribution and trends of tropospheric ozone: An observation-based review, Elementa-Sci. Anthrop., 2, 000029 , doi:10.12952/journal.elementa.000029, 2014.

Deser, C., Alexander, M. A., Xie, S.-P., and Phillips, A. S.: Sea Surface Temperature Variability: Patterns and Mechanisms, Annu. Rev Marine Sci., 2, 115-143, 2010.

Donner, L. J., Wyman, B. L., Hemler, R. S., Horowitz, L. W., Ming, Y., Zhao, M., Golaz, J.-C., Ginoux, P., Lin, S. J., Schwarzkopf, M. D., Austin, J., Alaka, G., Cooke, W. F., Delworth, T. L., Freidenreich, S. M., Gordon, C. T., Griffies, S. M., Held, I. M., Hurlin, W. J., Klein, S. A., Knutson, T. R., Langenhorst, A. R., Lee, H.-C., Lin, Y., Magi, B. I., Malyshev, S. L., Milly, P. C. D., Naik, V., Nath, M. J., Pincus, R., Ploshay, J. J., Ramaswamy, V., Seman, C. J., Shevliakova, E., Sirutis, J. J., Stern, W. F., Stouffer, R. J., Wilson, R. J., Winton, M., Wittenberg, A. T., and Zeng, F.: The Dynamical Core, Physical Parameterizations, and Basic Simulation Characteristics of the Atmospheric Component AM3 of the GFDL Global Coupled Model CM3, J. Climate, 24, 34843519, 2011.

Finlayson-Pitts, B. J. and Pitts, J. N.: Tropospheric Air Pollution: Ozone, Airborne Toxics, Polycyclic Aromatic Hydrocarbons, and Particles, Science, 276, 1045-1051, 1997. 
Giglio, L., Randerson, J. T., and van der Werf, G. R.: Analysis of daily, monthly, and annual burned area using the fourthgeneration global fire emissions database (GFED4), J. Geophys. Res., 118, 317-328, 2013.

Guenther, A. B., Jiang, X., Heald, C. L., Sakulyanontvittaya, T., Duhl, T., Emmons, L. K., and Wang, X.: The Model of Emissions of Gases and Aerosols from Nature version 2.1 (MEGAN2.1): an extended and updated framework for modeling biogenic emissions, Geosci. Model Dev., 5, 1471-1492, doi:10.5194/gmd-51471-2012, 2012.

He, Y. J., Uno, I., Wang, Z. F., Pochanart, P., Li, J., and Akimoto, H.: Significant impact of the East Asia monsoon on ozone seasonal behavior in the boundary layer of Eastern China and the west Pacific region, Atmos. Chem. Phys., 8, 7543-7555, doi:10.5194/acp-8-7543-2008, 2008.

Henne, S., Brunner, D., Folini, D., Solberg, S., Klausen, J., and Buchmann, B.: Assessment of parameters describing representativeness of air quality in-situ measurement sites, Atmos. Chem. Phys., 10, 3561-3581, doi:10.5194/acp-10-3561-2010, 2010.

Lamarque, J.-F., Shindell, D. T., Josse, B., Young, P. J., Cionni, I., Eyring, V., Bergmann, D., Cameron-Smith, P., Collins, W. J., Doherty, R., Dalsoren, S., Faluvegi, G., Folberth, G., Ghan, S. J., Horowitz, L. W., Lee, Y. H., MacKenzie, I. A., Nagashima, T., Naik, V., Plummer, D., Righi, M., Rumbold, S. T., Schulz, M., Skeie, R. B., Stevenson, D. S., Strode, S., Sudo, K., Szopa, S., Voulgarakis, A., and Zeng, G.: The Atmospheric Chemistry and Climate Model Intercomparison Project (ACCMIP): overview and description of models, simulations and climate diagnostics, Geosci. Model Dev., 6, 179-206, doi:10.5194/gmd-6-179-2013, 2013.

Lelieveld, J., Butler, T. M., Crowley, J. N., Dillon, T. J., Fischer, H., Ganzeveld, L., Harder, H., Lawrence, M. G., Martinez, M., Taraborrelli, D., and Williams, J.: Atmospheric oxidation capacity sustained by a tropical forest, Nature, 452, 737-740, 2008.

Marenco, A., Goutget, H., Nédélec, P., and Pagés, J.-P.: Evidence of a long-term increase in tropospheric ozone from Pic du Midi data series: Consequences: Positive radiative forcing, J. Geophys. Res., 99, 16617-16632, 1994.

McDonnell, W. F., Muller, K. E., Bromberg, P. A., and Shy, C. M.: Predictors of Individual Differences in Acute Response to Ozone Exposure, Am. Rev. Respir. Dis., 147, 818-825, doi:10.1164/ajrccm/147.4.818, 1993.

Messié, M. and Chavez, F.: Global Modes of Sea Surface Temperature Variability in Relation to Regional Climate Indices, J. Climate, 24, 4314-4331, 2011.

Myhre, G., Shindell, D., Bréon, F.-M., Collins, W., Fuglestvedt, J., Huang, J., Koch, D., Lamarque, J.-F., Lee, D., Mendoza, B., Nakajima, T., Robock, A., Stephens, G., Takemura, T., and Zhang, H.: Anthropogenic and Natural Radiative Forcing, book section 8, Cambridge University Press, Cambridge, United Kingdom and New York, NY, USA, 659-740, 2013.

The Nature Conservancy: tnc_terr_ecoregions, available at: http: //maps.tnc.org/files/shp/terr-ecoregions-TNC.zip (last access: 31 July 2015), 2012.

Olson, D. M. and Dinerstein, E.: The Global 200: Priority ecoregions for global conservation, Ann. Mo. Bot. Gard., 89, 125-126, 2002.

Oman, L. D., Ziemke, J. R., Douglass, A. R., Waugh, D. W., Lang, C., Rodriguez, J. M., and Nielsen, J. E.: The response of tropical tropospheric ozone to ENSO, Geophys. Res. Lett., 38, L13706, doi:10.1029/2011GL047865, 2011.

Parrella, J. P., Jacob, D. J., Liang, Q., Zhang, Y., Mickley, L. J., Miller, B., Evans, M. J., Yang, X., Pyle, J. A., Theys, N., and Van Roozendael, M.: Tropospheric bromine chemistry: implications for present and pre-industrial ozone and mercury, Atmos. Chem. Phys., 12, 6723-6740, doi:10.5194/acp-12-6723-2012, 2012.

Pedregosa, F., Varoquaux, G., Gramfort, A., Michel, V., Thirion, B., Grisel, O., Blondel, M., Prettenhofer, P., Weiss, R., Dubourg, V., Vanderplas, J., Passos, A., Cournapeau, D., Brucher, M., Perrot, M., and Duchesnay, E.: Scikit-learn: Machine Learning in Python, J. Mach. Learn. Res., 12, 2825-2830, 2011.

The Royal Society: Ground-level ozone in the 21st century: future trends, impacts and policy implications, 20, 67-74, 2008.

Sitch, S., Cox, P. M., Collins, W. J., and Huntingford, C.: Indirect radiative forcing of climate change through ozone effects on the land-carbon sink, Nature, 448, 791-794, 2007.

Sofen, E. D., Evans, M. J., Bowdalo, D., Apadula, F., Bonasoni, P., Cupeiro, M., Ellul, R., Galbally, I. E., Girgzdiene, R., Luppo, S., Mimouni, M., Nahas, A. C., Saliba, M., Torseth, K., and all other contributors to WMO GAW, EPA AQS, EPA CASTNET, CAPMON, NAPS, AirBase, EMEP, EANET ozone datasets: Comprehensive global dataset of surface ozone observations for atmospheric chemistry model evaluation, Earth Syst. Sci. Data, in press, 2016.

Staehelin, J., Thudium, J., Buehler, R., Volz-Thomas, A., and Graber, W.: Trends in surface ozone concentrations at Arosa (Switzerland), Atmos. Environ., 28, 75-87, 1994.

Thompson, D. W. J. and Wallace, J. M.: The Arctic oscillation signature in the wintertime geopotential height and temperature fields, Geophys. Res. Lett., 25, 1297-1300, 1998.

Trenberth, K. E., Stepaniak, D. P., and Caron, J. M.: The Global Monsoon as Seen through the Divergent Atmospheric Circulation, J. Climate, 13, 3969-3993, 2000.

Volz, A. and Kley, D.: Evauluation of the Montsouris seris of ozone measurements made in the nineteenth century, Nature, 332, 240242, 1988.

Wang, F., Saiz-Lopez, A., Mahajan, A. S., Gómez Martín, J. C., Armstrong, D., Lemes, M., Hay, T., and Prados-Roman, C.: Enhanced production of oxidised mercury over the tropical Pacific Ocean: a key missing oxidation pathway, Atmos. Chem. Phys., 14, 1323-1335, doi:10.5194/acp-14-1323-2014, 2014.

Young, P. J., Archibald, A. T., Bowman, K. W., Lamarque, J.-F., Naik, V., Stevenson, D. S., Tilmes, S., Voulgarakis, A., Wild, O., Bergmann, D., Cameron-Smith, P., Cionni, I., Collins, W. J., Dalsøren, S. B., Doherty, R. M., Eyring, V., Faluvegi, G., Horowitz, L. W., Josse, B., Lee, Y. H., MacKenzie, I. A., Nagashima, T., Plummer, D. A., Righi, M., Rumbold, S. T., Skeie, R. B., Shindell, D. T., Strode, S. A., Sudo, K., Szopa, S., and Zeng, G.: Preindustrial to end 21st century projections of tropospheric ozone from the Atmospheric Chemistry and Climate Model Intercomparison Project (ACCMIP), Atmos. Chem. Phys., 13, 20632090, doi:10.5194/acp-13-2063-2013, 2013.

Zhang, J., Tian, W., Wang, Z., Xie, F., and Wang, F.: The Influence of ENSO on Northern Midlatitude Ozone during the Winter to Spring Transition, J. Climate, 28, 4774-4793, 2015.

Zhang, Y., Wallace, J. M., and Battisti, D. S.: ENSO-like Interdecadal Variability: 1900-93, J. Climate, 10, 1004-1020, 1997. 
Ziemke, J. R., Chandra, S., Oman, L. D., and Bhartia, P. K.: A new ENSO index derived from satellite measurements of column ozone, Atmos. Chem. Phys., 10, 3711-3721, doi:10.5194/acp10-3711-2010, 2010.

Ziemke, J. R., Douglass, A. R., Oman, L. D., Strahan, S. E., and Duncan, B. N.: Tropospheric ozone variability in the tropics from ENSO to MJO and shorter timescales, Atmos. Chem. Phys., 15, 8037-8049, doi:10.5194/acp-15-8037-2015, 2015.
Zoogman, P., Jacob, D. J., Chance, K., Zhang, L., Sager, P. L., Fiore, A. M., Eldering, A., Liu, X., Natraj, V., and Kulawik, S. S.: Ozone air quality measurement requirements for a geostationary satellite mission, Atmos. Environ., 45, 7143-7150, 2011. 